\title{
Imbalanced adaptive responses associated with microsatellite instability in cholangiocarcinoma
}

\author{
WATCHARIN LOILOME ${ }^{1,2}$, SASITHORN KADSANIT $^{1,2}$, KANHA MUISOOK $^{3}$, PUANGRAT YONGVANIT $^{1,2}$, \\ NISANA NAMWAT ${ }^{1,2}$, ANCHALEE TECHASEN ${ }^{2,4}$, ANUCHA PUAPAIROJ ${ }^{2,5}$, \\ NARONG KHUNTIKEO ${ }^{2,6}$ and PICHAI PHONJIT ${ }^{6}$ \\ ${ }^{1}$ Department of Biochemistry, Faculty of Medicine; ${ }^{2}$ Liver Fluke and Cholangiocarcinoma Research Center; \\ ${ }^{3}$ Department of Forensics Science, Faculty of Medicine; ${ }^{4}$ Department of Medical Technology, \\ Faculty of Associated Medical Science; ${ }^{5}$ Department of Pathology, Faculty of Medicine; \\ ${ }^{6}$ Department of Surgery, Faculty of Medicine, Khon Kaen University, Khon Kaen 40002, Thailand
}

Received July 3, 2015; Accepted October 25, 2016

DOI: $10.3892 / \mathrm{ol} .2016 .5477$

\begin{abstract}
The adaptive response of the genome protection mechanism occurs in cells when exposed to genotoxic stress due to the overproduction of free radicals via inflammation and infection. In such circumstances, cells attempt to maintain health via several genome protection mechanisms. However, evidence is increasing that this adaptive response may have deleterious effect; a reduction of antioxidant enzymes and/or imbalance in the DNA repair system generates microsatellite instability (MSI), which has procarcinogenic implications. Therefore, the present study hypothesized that MSI caused by imbalanced responses of antioxidant enzymes and/or DNA repair enzymes as a result of oxidative/nitrative stress arising from the inflammatory response is involved in liver fluke-associated cholangiocarcinogenesis. The present study investigated this hypothesis by identifying the expression patterns of antioxidant enzymes, including superoxide dismutase 2 (SOD2) and catalase (CAT), and DNA repair enzymes, including alkyladenine DNA glycosylase (AAG), apurinic endonuclease (APE) and DNA polymerase $\beta$ (DNA pol $\beta$ ). In addition, the activities of the antioxidant enzymes, SOD2 and CAT, were examined in human cholangiocarcinoma (CCA) tissues using immunohistochemical staining. MSI was also analyzed in human CCA tissues. The resulting data demonstrated that the expression levels of the SOD2 and CAT enzymes decreased. The activities of SOD2 and CAT decreased significantly in the CCA tissues, compared with the hepatic tissue of cadaveric donors. In the DNA repairing enzymes, it was found that the
\end{abstract}

Correspondence to: Dr Watcharin Loilome, Department of Biochemistry, Faculty of Medicine, Khon Kaen University, 123 Mitraphab Road, Khon Kaen 40002, Thailand

E-mail:watloi@yahoo.com

Key words: cholangiocarcinoma, imbalanced adaptive responses, microsatellite instability, antioxidant enzymes, DNA repairing enzymes expression levels of AAG and DNA pol $\beta$ enzymes increased, whereas the expression of APE decreased. In addition, it was found that MSI-high was present in $69 \%$ of patients, whereas MSI-low was present in $31 \%$ of patients, with no patients classified as having microsatellite stability. In the patients, a MSI-high was correlated with poor prognosis, indicated by a shorter survival rate. These results indicated that the reduction of antioxidant enzymes and adaptive imbalance of base excision repair enzymes in human CCA caused MSI, and may be associated with the progression of cancer.

\section{Introduction}

Cholangiocarcinoma (CCA) is a malignant tumor arising from bile duct epithelial cells, which is the most common form of cancer in Thailand and a major public health problem in the northeast region (1). Several epidemiological and experimental studies have provided support that liver fluke (Opisthorchis viverrini; Ov) infection is the etiological factor underlying the development of CCA (2-4). The mechanistic link between host-parasite interaction and CCA carcinogenesis has been reviewed previously (5). Our previous studies in a hamster animal model revealed that chronic inflammation induced by repeated Ov infection was a risk factor for CCA. Increased frequency $\mathrm{Ov}$ infections can induce the accumulation of inducible nitric oxide synthase (iNOS) in inflammatory cells and in the epithelium of bile ducts, and subsequently causes nitrative and oxidative damage to nucleic acids. In addition, NO may be involved in carcinogenesis through heme oxygenase-1-derived iron accumulation, which may be involved in the enhancement of oxidative DNA damage in the epithelium of small bile ducts (6-9). It can be concluded that repeated infection with Ov mediates oxidative and nitrative DNA damage, and may be involved in the initiation and/or promotion of CCA carcinogenesis through chronic inflammation. Inflammatory cell infiltration triggered by repeated infections has been shown to occur earlier than in single infections, and is associated with alterations in liver enzymes and the severity of periductal fibrosis (7). Furthermore, Thanan et al (10) reported that humans infected with Ov had an accumulation of urinary 8-oxo-7, 
8-dihydro-2'-deoxyguanosine, which was positively associated with plasma levels of nitrate/nitrite and aspartate transaminase, indicating that $\mathrm{Ov}$ infection can induce oxidative and nitrative stress via the production of reactive oxygen and reactive nitrogen species during liver injury in humans. In addition, DNA damage due to Ov infection-mediated lipid peroxidation has been reported in animal and human studies (11-13). Several cellular proteins in CCA tissue have been found to exist in carbonylated forms via oxidative damage and subsequent dysfunction, leading to the progression of CCA (14). The evidence to date suggests an association between $\mathrm{Ov}$ infection, chronic inflammation and subsequent CCA development.

The adaptive response of the genome protection mechanism occurs in cells exposed to stress due to the overproduction of free radicals via the inflammatory process and infection. In such circumstances, cells maintain health via several genome protection mechanisms. However, there is increasing evidence that this adaptive response may have deleterious effects, for example if there is a reduction of antioxidant enzymes and/ or imbalance in the DNA repair system, as this generates microsatellite instability (MSI), which has procarcinogenic implications. Evidence to support these effects have been shown in studies by Guner et al (15) and Hofseth et al (16). These studies reported that low levels of antioxidant enzymes in cancerous tissues were in the carcinogenic process and that the adaptive imbalance in basal levels of excision-repair enzymes generates MSI in chronic inflammation. Our previous study (17) revealed impairment of antioxidant enzyme activity and increased expression of DNA repair enzymes in hamster liver tissues, which were associated with the development of cholangiocarcinoma in a hamster model.

Therefore, the present study hypothesized that MSI, caused by imbalanced responses of antioxidant enzymes and/or DNA repair enzymes due to oxidative/nitrative stress from the inflammatory response, is involved in Ov-associated cholangiocarcinogenesis. To confirm this hypothesis, the present study aimed to identify the expression patterns of the antioxidant enzymes, superoxide dismutase type 2 (SOD2) and catalase (CAT), and the DNA repair enzymes, alkyladenine DNA glycosylase (AAG), apurinic endonuclease (APE) and DNA polymerase $\beta$ (DNA pol $\beta$ ), in addition to determining the activites of the SOD2 and CAT antioxidant enzymes in human and hamster CCA tissues. MSI was investigated in human CCA tissues only. The results may provide additional knowledge to explain the procarcinogenic effect of cholangiocarcinoma caused by $\mathrm{OV}$ infection.

\section{Materials and methods}

White blood cells (WBCs) and cholangiocarcinoma tissues. A total of 13 surgically resected liver specimens of CCA patients and their WBCs were selected from the tissue bank of the Liver Fluke and Cholangiocarcinoma Research Center at Khon Kaen University (Khon Kaen, Thailand). Of the 13 CCA patients studied, $69 \%$ were male, resulting in a male to female ratio of 2.25:1. The mean age was $53.9 \pm 8.9$ years (range, $37-64$ years). The control group $(n=5)$ comprised liver tissue obtained from cadaveric donors who had succumbed to a car accident, and their kidneys were harvested for transplantation. Informed consent was obtained from individual patients and donors' relatives. The protocols for collection and experiments were approved by the Ethics Committee for Human Research, Khon Kaen University (approval no. HE571283).

Antibodies. The antibodies used for immunohistochemical staining were as follows: Rabbit anti-SOD2 polyclonal antibody (dilution, 1:200; EMD Millipore, Billerica, MA, USA), rabbit anti-CAT polyclonal antibody (dilution, 1:1,000; Abcam, Cambridge, MA, USA), goat anti-AAG polyclonal antibody (dilution 1:100; Abcam), rabbit anti-DNA pol $\beta$ antibody (dilution 1:50; Abcam) and mouse anti-APE1 monoclonal antibody (dilution 1:50, Santa Cruz Biotechnology, Inc., Dallas, TX, USA).

Immunohistochemical investigation of antioxidant and DNA repair enzymes. An immunohistochemical method was used to determine the expression patterns of antioxidant enzymes and DNA repair enzymes in human CCA tissues. Sections (size, $1.5 \times 2 \mathrm{~cm}$; thickness, $4 \mu \mathrm{m}$ ) of human liver tissues were deparaffinized and rehydrated in a stepwise manner with decreasing concentrations of ethanol. Antigen retrieval was performed via microwave treatment in $10 \mathrm{mM}$ citrate buffer ( $\mathrm{pH}$ 6.0) at high power for $10 \mathrm{~min}$, following which the sections were immersed for $20 \mathrm{~min}$ in $3 \%(\mathrm{v} / \mathrm{v})$ hydrogen peroxide in PBS to inhibit endogenous hydrogen peroxide activity. Nonspecific binding was blocked by skim milk in PBS for $30 \mathrm{~min}$. The sections were incubated with the primary antibodies in a moisture chamber for $1 \mathrm{~h}$ at room temperature and at $4^{\circ} \mathrm{C}$ overnight. Subsequently, the sections were washed in PBS and incubated with peroxidaseconjugated Envision ${ }^{\mathrm{TM}}$ secondary antibody (Dako, Glostrup, Denmark) in a moisture chamber for 1 hat room temperature. Following washing in PBS, the color was developed using a 3, 3'diaminobenzidine tetrahydrochloride substrate kit for $5 \mathrm{~min}$ and then counterstained with Mayer's haematoxylin. The sections were rehydrated in a stepwise-manner with increasing concentrations of ethanol, cleared with xylene and mounted with permount. The stained sections were viewed under a microscope (Axio Scope.A1; Carl Zeiss AG, Oberkochen, Germany). The protein expression levels were graded by calculating the total immunostaining index as the product of the frequency and intensity scores. The frequency score represented the estimated fraction of positively-stained tumor cells $(0=0 \%$; $1=1-25 \% ; 2=26-50 \% ; 3=>50 \%)$. The intensity score represented the estimated staining intensity $(0$, negative staining; 1 , weak; 2 , moderate; 3 , strong). The immunohistochemical index ranged between 0 and 9 . Negative, low, moderate and high expression levels of SOD2 and CAT were defined as immunohistochemical indices $0,1-2,3-4$ and $>4$, respectively. Omission of the primary antibody served as a negative control.

Investigation of enzymatic reactions of antioxidant enzymes. To examine the activity of SOD2, the frozen human CCA tissue was washed with PBS ( $\mathrm{pH}$ 7.4) to remove any red blood cells and clots. The tissue was homogenized in $1 \mathrm{ml}$ of cold $20 \mathrm{mM}$ HEPES buffer ( $\mathrm{pH}$ 7.2), which consisted of $1 \mathrm{mM}$ EGTA, $210 \mathrm{mM}$ mannitol and $70 \mathrm{mM}$ sucrose. The homogenate was centrifuged at $1,500 \mathrm{x} \mathrm{g}$ for $5 \mathrm{~min}$ at $4^{\circ} \mathrm{C}$ and the supernatant was removed to assess total SOD activity (cytosolic and mitochondrial). To separate the two compartments of the enzymes, $1,500 \mathrm{x} g$ supernatant was centrifuged at $10,000 \mathrm{x} \mathrm{g}$ for $15 \mathrm{~min}$ 
at $4^{\circ} \mathrm{C}$, the supernatant contained cytosolic SOD and the pellet contained mitochondrial SOD. The mitochondrial pellet was homogenized in HEPES buffer to determine mitochondrial SOD2 activity.

To determine the activity of CAT, the frozen human CCA tissue was washed with PBS ( $\mathrm{pH}$ 7.4) to remove any red blood cells and clots. The tissue was homogenized in $1 \mathrm{ml}$ of $50 \mathrm{mM}$ potassium phosphate ( $\mathrm{pH} 7.0$ ), containing $1 \mathrm{mM}$ EDTA, and the homogenate was centrifuged at $10,000 \times \mathrm{g}$ for $15 \mathrm{~min}$ at $4^{\circ} \mathrm{C}$ to extract proteins. The supernatant was used to assess the activity of CAT.

Subsequently, the extracted SOD2 and CAT proteins were used for enzymatic reactions. SOD and CAT assay kits were purchased from Cayman Chemical Company (Ann Arbor, MI, USA. The principle of the SOD assay kit is that it utilizes a tetrazolium salt for the detection of superoxide radicals generated by xanthine oxidase and hypoxanthine. The absorbance was measured at 440-460 $\mathrm{nm}$ on an ELISA reader (Tecan, Männedorf, Switzerland). An SOD level of 1 unit was considered the quantity of enzyme required to exhibit $50 \%$ dismutation of the superoxide radical. The CAT assay kit utilizes the peroxidatic function of CAT to determine enzyme activity. The method is based on the reaction of the enzyme with methanol, in the presence of an optimal concentration of $\mathrm{H}_{2} \mathrm{O}_{2}$. The formaldehyde produced is measured spectrophotometrically with 4-amino-3-hydrazino-5-mercapto-1, 2, 4-trizazole as the chromogen. The absorbance was read at $540 \mathrm{~nm}$ using an ELISA reader (Tecan). The activity of SOD is presented as $\mathrm{U} / \mathrm{ml} / \mathrm{mg}$ protein, whereas the activity of CAT activity is presented as $\mu \mathrm{M} / \mathrm{min} / \mathrm{mg}$ protein.

DNA extraction. The paraffinized sections of CCA tissue were deparaffinized twice in xylene for $5 \mathrm{~min}$ to remove the paraffin wax. Following deparaffinization, the slide was hydrated in decreasing concentrations of ethanol (absolute alcohol for $3 \mathrm{~min}$; $70 \%$ alcohol for $3 \mathrm{~min}$ ) and rinsed in tap water. Following hydration, the slide was stained with hematoxylin for $5 \mathrm{~min}$, washed in running tap water for $2 \mathrm{~min}$, destained in acid alcohol (1\% acid in $70 \%$ alcohol), washed in running tap water again, and dehydrated (70\% alcohol for $2 \mathrm{~min}$; absolute alcohol for $2 \mathrm{~min}$ ) twice. Successful staining of the nuclei was indicated by a blue color. Following visualization under an Axio Scope.A1 microscope (Carl Zeiss AG) and separation of tumorous and non-tumorous tissues, extraction was performed using a QIAamp DNA formalin-fixed paraffin-embedded tissue kit (Qiagen, Inc., Valencia, CA, USA). Matched WBCs were prepared for DNA extraction by digestion in $1 \mathrm{ml}$ of lysis buffer, $0.2 \mu \mathrm{l}$ of $10 \mathrm{mg} / \mathrm{ml}$ RNase and $10 \mu \mathrm{l}$ of $17 \mathrm{mg} / \mathrm{ml}$ proteinase $\mathrm{K}$ at $50^{\circ} \mathrm{C}$ for $30 \mathrm{~min}$. Protein was precipitated by adding $300 \mu \mathrm{l}$ of $\mathrm{NaI}$ solution. Isopropanol was added to the supernatant in order to precipitate DNA. The DNA pellet was then resuspended in TE buffer ( $\mathrm{pH}$ 8.0).

MSI analysis. The DNA extracted from tumor tissues, non-tumor tissues of the adjacent area and WBCs of the same patient were analyzed for MSI using five microsatellite markers: BAT25, BAT26, D5S346, D2S123 and D17S250 (18). Oligonucleotide forward primers were fluorescent-5'-labeled. Polymerase chain reaction (PCR) analysis was performed in a $20 \mathrm{ml}$ reaction mixture with $10-100 \mathrm{ng}$ genomic DNA,
$0.2 \mathrm{mM}$ of each dNTP, 1X high fidelity PCR buffer, $0.2 \mu \mathrm{M}$ of each primer and 1 unit Taq DNA polymerase high fidelity (Invitrogen; Thermo Fisher Scientific, Inc., Waltham, MA, USA). The sequences of each primer are shown in Table I. The amplification conditions for BAT25, BAT26 and D17S250 were as follows: $5 \mathrm{~min}$ initial denaturation at $94^{\circ} \mathrm{C}$, followed by 30 cycles of $30 \mathrm{sec}$ at $94^{\circ} \mathrm{C}, 30 \mathrm{sec}$ at $50^{\circ} \mathrm{C}$ and $1 \mathrm{~min}$ at $68^{\circ} \mathrm{C}$, with a final extension of $10 \mathrm{~min}$ at $68^{\circ} \mathrm{C}$. The amplification conditions for D2S123 and D5S346 were as follows: 5 min initial denaturation at $94^{\circ} \mathrm{C}$, followed by 30 cycles of $30 \mathrm{sec}$ at $94^{\circ} \mathrm{C}, 30 \mathrm{sec}$ at $55^{\circ} \mathrm{C}$ and $1 \mathrm{~min}$ at $68^{\circ} \mathrm{C}$, with a final extension of $10 \mathrm{~min}$ at $72^{\circ} \mathrm{C}$. The MSI was then analyzed in an ABI Prism 3130 genetic analyzer (Applied Biosystems; Thermo Fisher Scientific, Inc.) using GeneScan Analysis v3.2.1 software (Applied Biosystems; Thermo Fisher Scientific, Inc). MSI was indicated as alterations in the densities of bands observed in the tumor tissue and non-tumor of adjacent area, which were not present in the normal control WBCs from the same patient. Tumors exhibiting MSI at two or more markers were defined as MSI-high (MSI-H). Tumors showing instability at only one marker were defined as MSI-low (MSI-L). Tumors in which no markers exhibited MSI were considered to show microsatellite stability (MSS).

Statistical analysis. Statistical analysis was performed using GraphPad Prism version 5 (GraphPad Software Inc., La Jolla, CA, USA). The Mann-Whitney U test was used to compare differences between the cadaveric donor and human CCA. Clinicopathological characteristics and MSI (low and high) in human CCA tissues were compared using Fisher's exact probability test. The Kaplan-Meier method was used to calculate the survival curves, and the Log-rank test was performed to compare differences in the survival rates of patients who were subjected to curative surgery. $\mathrm{P}<0.05$ was considered to indicate a statistically significant difference.

\section{Results}

Protein expression of antioxidant enzymes and DNA repair enzymes in human CCA tissues. Immunohistochemical analysis was performed to detect the expression levels of SOD2 and CAT in human CCA tissues. The results demonstrated that SOD2 and CAT were expressed in the cytosolic bile duct CCA tissues. The majority of the normal bile duct epithelia in the tissues adjacent to the tumor sections stained positively for SOD2 and CAT. The expression of SOD2 and CAT were also observed in hepatocytes. The numbers of samples with SOD2 at low, moderate and high levels of expression were $15(55 \%)$, eight $(30 \%)$ and four $(15 \%)$, respectively, whereas the number of samples with CAT at negative, low, moderate and high levels of expression were four (15\%), 11 (40\%), eight $(30 \%)$ and four $(15 \%)$, respectively. The representative results of SOD2 and CAT staining in the CCA tissue are shown in Fig. 1A-D.

The present study also examined the expression levels of AAG, APE and DNA pol $\beta$ in human CCA tissues using immunohistochemistry. The results showed that AAG, APE and DNA pol $\beta$ were expressed in the nuclei of bile duct CCA tissues. In the normal bile duct epithelia residing in tissue adjacent to the tumor sections, weak staining for AAG, APE 
Table I. Specific primers for microsatellite polymerase chain reaction analysis.

\begin{tabular}{|c|c|c|}
\hline Primer & Linked gene & Sequence \\
\hline BAT25 & c-kit & $\begin{array}{l}\text { Forward 5'-TCG CCT CCA AGA ATG TAA GT-3' } \\
\text { Reverse 5'-TCT GCA TTT TAA CTA TGG CTC-3' }\end{array}$ \\
\hline BAT26 & hMSH2 & $\begin{array}{l}\text { Forward 5'-TGA CTA CTT TTG ACT TCA GCC-3' } \\
\text { Reverse 5'-AAC CAT TCA ACA TTT TTA ACC C-3' }\end{array}$ \\
\hline D2S123 & hMSH2 & $\begin{array}{l}\text { Forward 5'-ACA TTG CTG GAA GTT CTG GC-3' } \\
\text { Reverse 5'-CCT TTC TGA CTT GGA TAC CA-3' }\end{array}$ \\
\hline D5S346 & APC & $\begin{array}{l}\text { Forward 5'-ACT CAC TCT AGT GAT AAA TCG G-3' } \\
\text { Reverse 5'-GTT TCC ATT GTA GCA TCT TGA C-3' }\end{array}$ \\
\hline $\mathrm{D} 17 \mathrm{~S} 250$ & p53 & $\begin{array}{l}\text { Forward 5'-GCT GGC CAT ATA TAT ATT TAA ACC-3' } \\
\text { Reverse 5'-GGA AGA ATC AAA TAG ACA AT-3' }\end{array}$ \\
\hline
\end{tabular}

MSH2, MutS omolog 2; APC, Adenomatous Polyposis Coli.

A

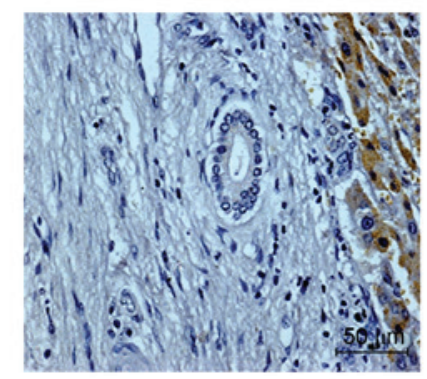

E

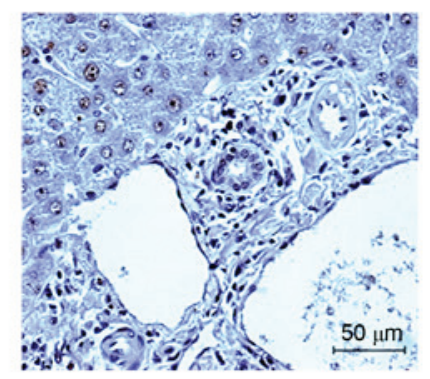

B

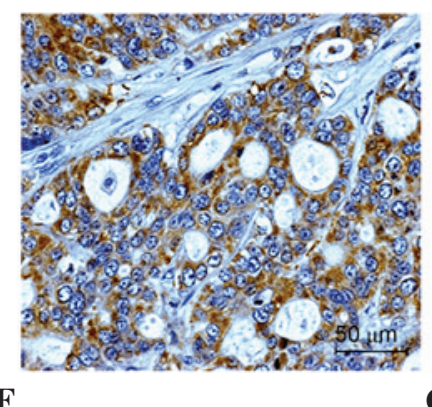

F

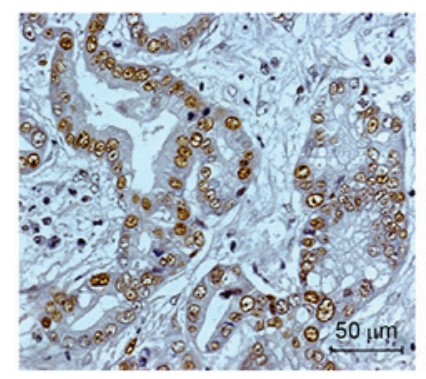

C

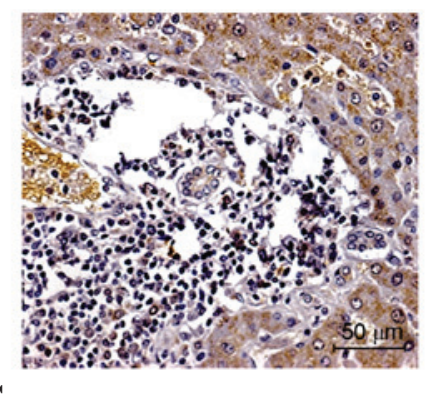

G

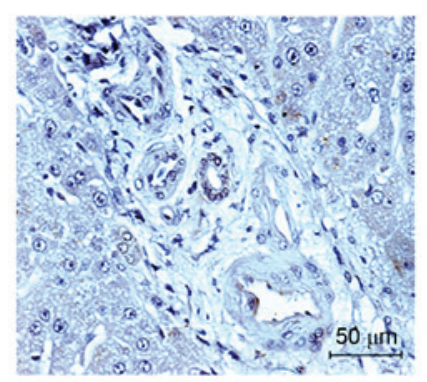

D

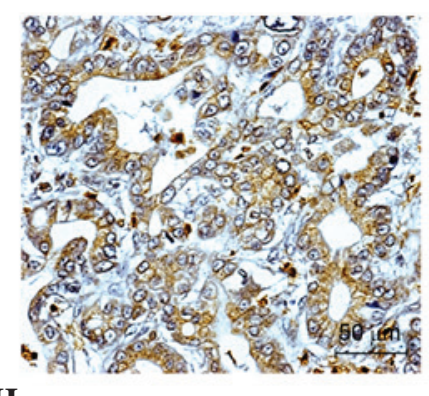

H

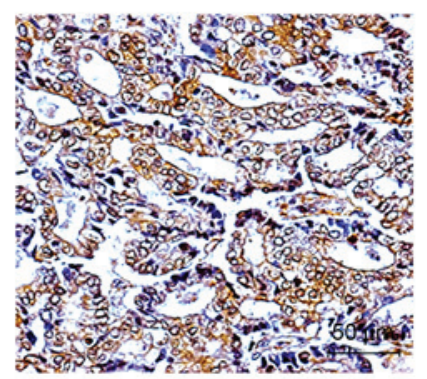

I

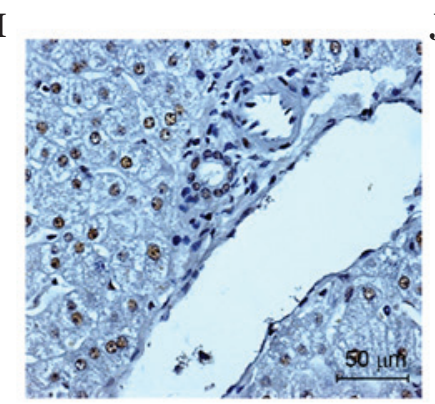

J

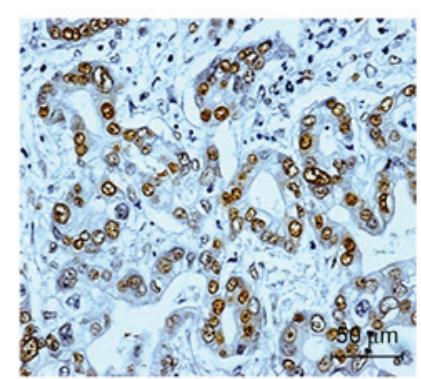

Figure 1. Immunohistochemical analysis of antioxidant enzymes and DNA repair enzyme in normal bile duct and cancer cells of human cholangiocarcinoma tissues. Enzymes included superoxide dismutase 2 in the (A) normal bile duct and (B) cancer cells, catalase in the (C) normal bile duct and (D) cancer cells, alkyladenine DNA glycosylase in the (E) normal bile duct and (F) cancer cells, apurinic endonuclease in the (G) normal bile duct and (H) cancer cells, and DNA polymerase $\beta$ in the (I) normal bile duct and (J) cancer cells. The original magnification was 100x for normal bile duct and 400x for cancer cells.

and DNA pol $\beta$ were observed. In the hepatocytes, positive staining was observed for AAG and DNA pol $\beta$, but not for APE (Fig. 1). The numbers of samples with low, moderate and high expression levels of AAG were four (15\%), eight (30\%) and 15 (55\%), respectively; numbers of samples with negative, low, moderate and high expression levels of APE were five $(19 \%), 15(55 \%)$, five $(19 \%)$ and two $(7 \%)$, respectively. The number of samples with DNA pol $\beta$ with moderate and high 
Table II. Microsatellite marker analysis and MSI status.

\begin{tabular}{lcccccc}
\hline \multicolumn{7}{c}{ Microsatellite marker } \\
\cline { 2 - 6 } Patient ID & BAT25 & BAT26 & D2S123 & D5S346 & D17S250 & MSI diagnosis \\
\hline R23 & + & - & + & - & + & MSI-high \\
R26 & + & - & + & - & + & MSI-high \\
R49 & + & - & - & - & - & MSI-low \\
R52 & + & - & - & - & - & MSI-low \\
R81 & + & - & - & + & + & MSI-high \\
R100 & + & - & + & + & - & MSI-high \\
R101 & - & - & - & + & - & MSI-high \\
R103 & - & - & + & + & - & MSI-low \\
R104 & + & - & + & + & - & MSI-high \\
R118 & - & - & - & + & - & MSI-high \\
R123 & + & - & + & - & MSI-low \\
R134 & - & - & + & MSI-high \\
R149 & & - & - & + & - \\
\hline
\end{tabular}

MSI, microsatellite instability.
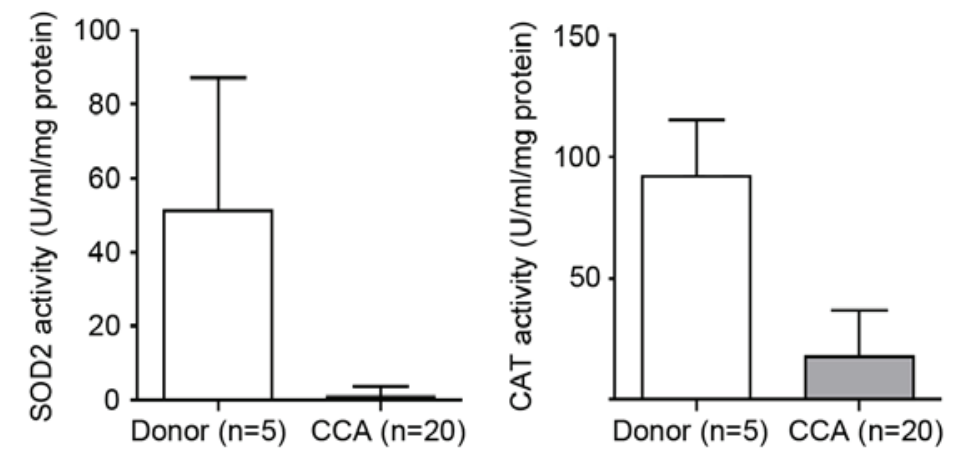

Figure 2. Activities of SOD2 and CAT in CCA and cadaveric donor tissues. A Mann-Whitney U test was used to analyze the statistical significance between the CCA and cadaveric donor samples. Data are presented as the mean + standard deviation. ${ }^{\text { }} \mathrm{P}<0.05$ between CCA and cadaveric donor. CCA, cholangiocarcinoma; SOD2, superoxide dismutase 2; CAT, catalase.

levels of expression were eight (30\%) and $19(70 \%)$, respectively. The representative results of AAG, APE and DNA pol $\beta$ in the patients with CCA are shown in Fig. 1E-J.

Activities of antioxidant enzymes in human CCA tissues. The activities of SOD2 and CAT were examined in human CCA tissues. The results showed that the activities of SOD2 and CAT were significantly decreased in the CCA tissues, compared with the tissues from the cadaveric donors $(\mathrm{P}=0.04$ and $\mathrm{P}=0.004$, respectively), as shown in Fig. 2 .

MSI analysis in human CCA tissues. The present study examined MSI in 13 patients with CCA using five microsatellite markers (18). MSI was indicated by altered band density in the tumor tissue and adjacent non-tumor tissue, which was not present in normal control WBCs from the same patient. The results are presented in Table II. Of the 13 CCA samples, four $(31 \%)$ were identified as MSI-low and nine (69\%) were identified as MSI-high. None of the cases exhibited MSS. A representative electropherograms from the assessment of MSI are shown in Fig. 3A-C.

The present study compared the clinical and histological tumor characteristics of the MSI-high tumors with those of the MSI-low tumors. No differences were observed in age, gender, histological type or metastasis. In comparing the patients with MSI-low and patients with MSI-high, the 5-year survival rate of the patients in the MSI-low ( $n=4)$ group was $31 \%$, whereas that of the patients in the MSI-high ( $n=9)$ group was $69 \%$, indicating that the survival rate was higher in the MSI-low group, as shown in Fig. 4. However, no significant difference between these two groups was found $(\mathrm{P}=0.14)$. Of note, the expression of APE showed a significant negative correlation with MSI status (Spearman's rank correlation test, -0.639; $\mathrm{P}=0.019$ ).

\section{Discussion}

Impairment of the antioxidant system may favor the accumulation of free radicals, as it has been found that low levels of 
A

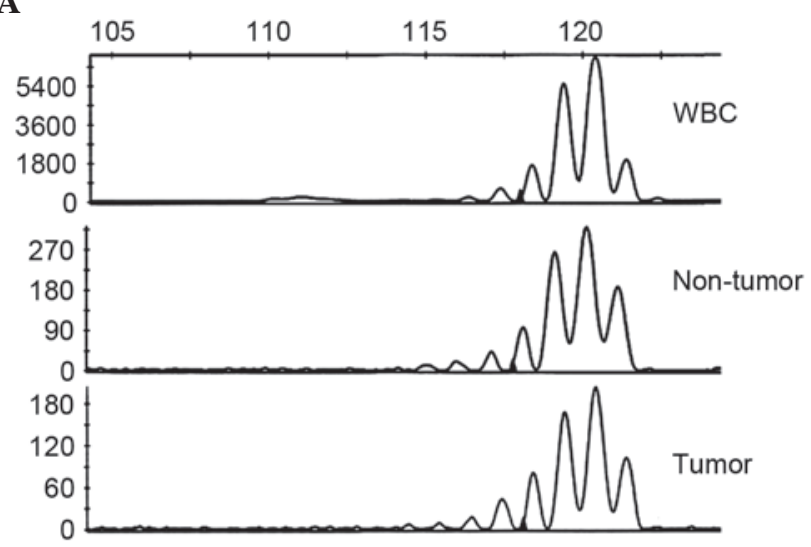

B
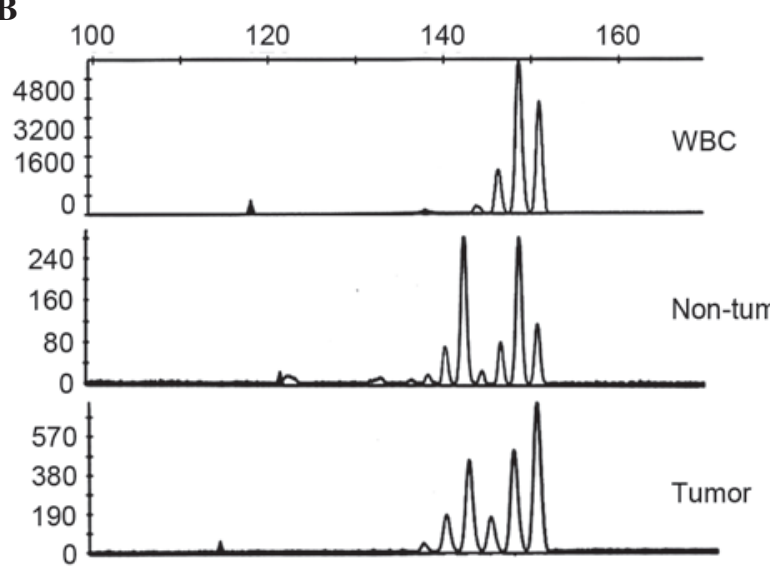

C

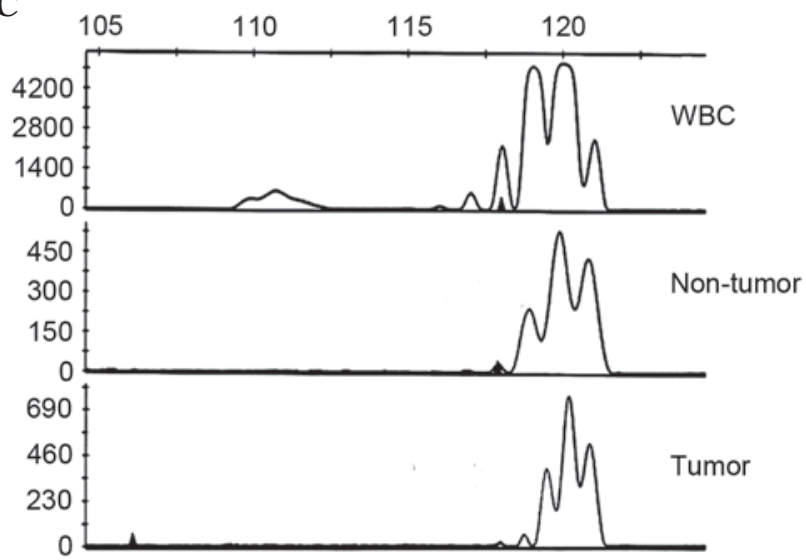

Figure 3. Representative electropherogram for the assessment of MSI. Size in $\mathrm{bp}$ is shown on the $\mathrm{x}$-axis at the top of the figure and the peak heights in fluorescence are shown on the y-axis on the left. The upper trace shows alleles of the WBCs, the middle trace shows alleles of the non-tumor tissue and the lower trace shows those of the corresponding tumor tissue. Examples of a (A) microsatellite stability case, (B) MSI-insertion case and (C) MSI-deletion case are shown. The arrow indicates abnormal allelic shifts. MSI, microsatellite instability; WBC, white blood cell.

essential antioxidants are associated with an increased risk of cancer (19). The results of the present study demonstrated a significant decrease in the expression levels of the SOD2 and CAT enzymes in human CCA tissue. This result was consistent with a previous observation in prostatic adenocarcinoma (20), which demonstrated that the expression levels of SOD2 and

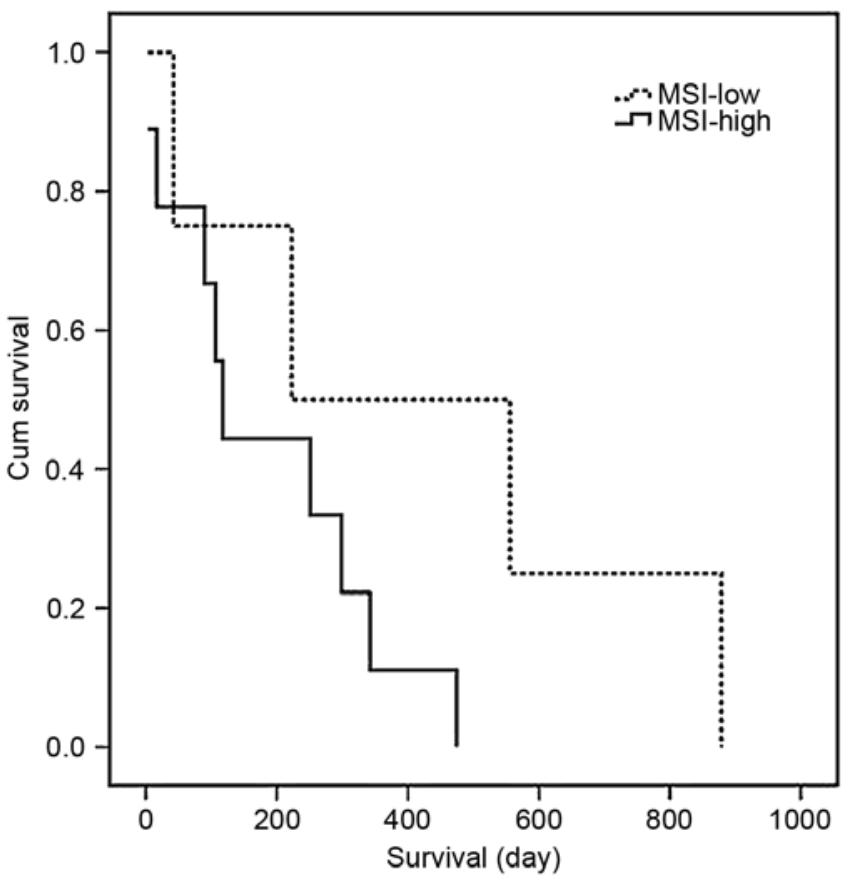

Figure 4. Five-year survival curve of MSI. The Kaplan-Meier method was used to establish the five-year survival curve. Patients with MSI-low had higher survival rates, compared with those with MSI-high cholangiocarcinoma $(\mathrm{P}=0.14)$. MSI, microsatellite instability.

CAT were significantly lower in cancer tissue, compared with than that in normal tissue. In addition, the present study found that the activities of SOD2 and CAT in human CCA were significantly decreased, compared with those in the cadaveric donor. Decreased activities of SOD and CAT, and an increase in DNA lesions have been suggested to be caused by free radicals in lung cancer tissues in humans (21). In conjunction with these results, Guner et al (15) found lower total activities of SOD and CAT in lung carcinoma tissue. It has also been demonstrated that levels of lipid peroxidation products and nitric oxide products are significantly elevated, whereas the levels of SOD and CAT enzymes are significantly lower in patients with oral cancer, compared with normal healthy subjects (22).

The induction of an oxidant-generating system and reduction of an antioxidant system are well-recognized causes of oxidative stress. Oxidant-generating enzymes, including inducible iNOS and cyclooxygenase 2 have been found to be upregulated in animals with Ov-induced CCA, in vitro cell lines and clinical samples of CCA (23-25). Plasma levels of nitrate/nitrite, which are by-products of reactive nitrogen species, are significantly increased in Ov-infected subjects and patients with Ov-associated CCA, compared with uninfected healthy subjects (10). In addition, inflammatory cytokines induce the formation of NO, and suppress the redox ratios of glutathione and glutathione disulfide in CCA cells (26). Previously, a significant decrease in the protein expression of manganese-SOD was reported in the cancer cells of CCA tissues, compared with individual normal bile duct cells located in regions adjacent to the tumor (14). Furthermore, the results of our previous study showed that the decreased gene expression of CAT in the peripheral blood leukocytes of patients with 
opisthorchiasis is induced by Ov antigen (27). Additionally CAT was found to be downregulated in an animal model of opisthorchaiasis-associated CCA, detected via kinetic analysis using the cDNA microarray technique (28).

These results are in agreement with those on an associated liver fluke, Fasciola hepatica, in which antioxidant potential was also shown to decrease in rat livers following infection (29). This reduction of antioxidant systems may increase oxidative damage to a wide range of biomolecules, including DNA, lipids, carbohydrates and proteins. The oxidation of lipids by excess levels of reactive oxygen species/reactive nitrogen species generates by-products including trans-4-hydroxy-2- nonenal, malondialdehyde and crotonaldehyde, which can react with DNA bases to form a variety of exocyclic DNA adducts (30-32). An increase in the formation of 1,N(6)-etheno-2'-deoxyadenosine and 3,N(4)-etheno-2'-deoxycytidine in CCA tissues has been revealed $(11,12)$. These etheno modified DNA bases are miscoding lesions, which are considered to contribute to the initiation of carcinogenesis through the induction of specific point mutations in DNA. Therefore, base excision repair (BER) is a key pathway used in the protection of free radical attack on DNA (33). The present study revealed increased expression levels of the AAG and DNA pol $\beta$ enzymes, whereas the expression of APE decreased.

The present study also found MSI-low (31\%) and MSI-high (69\%) in human CCA tissues. MSI-high was correlated with poor prognosis in patients, as indicated by shorter survival rates, compared with the group of MSI-low patients; however, this was not statistically significant, which may be due to the small sample size. Liengswangwong et al reported MSI-low and MSS in liver fluke infection-associated intrahepatic CCA (34). In addition, the prognostic and predictive impacts of MSI status in patients with colon cancer have been reported $(35,36)$. Previously, it was demonstrated the generation of a mutator phenotype in yeast was caused by imbalanced BER (37). The data obtained suggested a mechanism by which spontaneous mutation rates may be modulated. An imbalance between apurinic/apyrimidinic (AP) endonuclease and one particular DNA glycosylase produced a mutator phenotype in yeast. Imbalance in the glycosylase to AP endonuclease ratio may arise by promoter mutations, which affect the expression of DNA repair genes. Imbalances in BER enzymes may represent a previously unrecognized source of increased cancer risk. Furthermore, imbalanced BER increases spontaneous mutation and alkylation sensitivity in Escherichia coli (38). In a previous study of human colon adenoma showing dysregulation of BER, a correlation was found between the expression of AAG and iNOS. Nitration in the AAG active site of tyrosine 162 in vitro was found to impair $\varepsilon A$-excision activity, whereas nitrosation of cysteine 167 increased $\varepsilon$ A-excision activity. Therefore, the post-translational modification of AAG by reactive nitrogen species via the overproduction of NO appears to be one mechanism of BER dysregulation leading to malignancy (39). In ulcerative colitis, it has been shown that the adaptive imbalance in BER enzymes generates MSI in chronic inflammation.

Mechanistic studies using yeast and human cell models overexpressing AAG and/or APE1 were associated with frameshift mutations and MSI, indicating that the adaptive imbalanced increase in BER enzymes may have DNA-damaging effects and may contribute to carcinogenesis in chronic inflammation (16). Furthermore, studies have shown that the overexpression of DNA pol $\beta$ may be associated with MSI, which can lead to malignancy. DNA pol $\beta$ has a high level of infidelity in replicating DNA in vitro, due to the lack of associated proofreading activity and poor discrimination of nucleotides. This may be due to error-prone features, whereas the expression is tightly regulated in vivo, and constant and low throughout the cell-cycle (40). The overexpression of DNA pol $\beta$ in mammalian cells has been demonstrated to significantly increase mutation rate (41), which can consequently induce chromosomal instability and enhance the tumorigenicity of xenografts (42). Yamada and Farber (43) reported the induction of a low level of MSI by the overexpression of DNA pol $\beta$, and a mechanism was identified for the induction of microsatellite mutations by using a selection-based cell culture system with high sensitivity to relatively small increases in mutation rates. These results suggested that the overexpression of DNA pol $\beta$ may lead to increased genetic instability.

The results of the present study showed that a reduction in the expression of antioxidant enzymes and the adaptive imbalance of BER enzymes may cause MSI in human CCA. In addition, the results showed that patients with MSI-low had improved survival rates, compared with patients with MSI-high, which may increase susceptibility to tumorigenesis.

\section{Acknowledgements}

This study was supported by the Invitation Research Grant (grant no. I56130) and the Research Assistantship Grant of the Faculty of Medicine, Khon Kaen University (grant no. AS57202) to Dr Watcharin Loilomewl, the Scholarship of the Liver Fluke and Cholangiocarcinoma Research Center to Miss Sasithorn Kadsanitsk and grants from the Higher Education Research Promotion and National Research University Project of Thailand, Office of the Higher Education Commission, through the Center of Excellence in Specific Health Problems in Greater Mekong Sub-region cluster, Khon Kaen Universitym, allocated to Dr Watcharin Loilomewl. The authors would like to thank Professor Ross H Andrews for editing of the manuscript via Publication Clinic KKU, Thailand.

\section{References}

1. Khuntikeo N, Chamadol N, Yongvanit P, et al; CASCAP investigators: Cohort profile: Cholangiocarcinoma screening and care program (CASCAP). BMC Cancer 15: 459, 2015.

2. Flavell DJ and Lucas SB: Promotion of N-nitrosodimethylamineinitiated bile duct carcinogenesis in the hamster by the human liver fluke, Opisthorchis viverrini. Carcinogenesis 4: 927-930, 1983.

3. Ohshima $\mathrm{H}$ and Bartsch $\mathrm{H}$ : Chronic infections and inflammatory processes as cancer risk factors: Possible role of nitric oxide in carcinogenesis. Mutat Res 305: 253-264, 1994.

4. Thamavit W, Bhamarapravati N, Sahaphong S, et al: Effects of dimethylnitrosamine on induction of cholangiocarcinoma in Opisthorchis viverrini-infected Syrian golden hamsters. Cancer Res 38: 4634-4639, 1978.

5. Yongvanit $\mathrm{P}$, Pinlaor $\mathrm{S}$ and Bartsch $\mathrm{H}$ : Oxidative and nitrative DNA damage: Key events in opisthorchiasis-induced carcinogenesis. Parasitol Int 61: 130-135, 2012.

6. Pinlaor S, Hiraku Y, Ma N, Yongvanit P, Semba R, Oikawa S, Murata M, Sripa B, Sithithaworn P and Kawanishi S: Mechanism of NO-mediated oxidative and nitrative DNA damage in hamsters infected with Opisthorchis viverrini: A model of inflammation-mediated carcinogenesis. Nitric Oxide 11: 175-183, 2004. 
7. Pinlaor S, Ma N, Hiraku Y, Yongvanit P, Semba R, Oikawa S, Murata M, Sripa B, Sithithaworn P and Kawanishi S: Repeated infection with Opisthorchis viverrini induces accumulation of 8-nitroguanine and 8-oxo-7,8-dihydro-2'-deoxyguanine in the bile duct of hamsters via inducible nitric oxide synthase. Carcinogenesis 25: 1535-1542, 2004.

8. Pinlaor S, Sripa B, Sithithaworn P and Yongvanit P: Hepatobiliary changes, antibody response, and alteration of liver enzymes in hamsters re-infected with Opisthorchis viverrini. Exp Parasitol 108: 32-39, 2004

9. Pinlaor S, Yongvanit P, Hiraku Y, Ma N, Semba R, Oikawa S, Murata M, Sripa B, Sithithaworn P and Kawanishi S: 8-nitroguanine formation in the liver of hamsters infected with Opisthorchis viverrini. Biochem Biophys Res Commun 309: 567-571, 2003

10. Thanan R, Murata M, Pinlaor S, Sithithaworn P, Khuntikeo N, Tangkanakul W, Hiraku Y, Oikawa S, Yongvanit P and Kawanishi S: Urinary 8-oxo-7,8-dihydro-2'-deoxyguanosine in patients with parasite infection and effect of antiparasitic drug in relation to cholangiocarcinogenesis. Cancer Epidemiol Biomarkers Prev 17: 518-524, 2008.

11. Dechakhamphu S, Pinlaor S, Sitthithaworn P, Bartsch $\mathrm{H}$ and Yongvanit P: Accumulation of miscoding etheno-DNA adducts and highly expressed DNA repair during liver fluke-induced cholangiocarcinogenesis in hamsters. Mutat Res 691: 9-16, 2010

12. Dechakhamphu S, Pinlaor S, Sitthithaworn P, Nair J, Bartsch H and Yongvanit P: Lipid peroxidation and etheno DNA adducts in white blood cells of liver fluke-infected patients: Protection by plasma alpha-tocopherol and praziquantel. Cancer Epidemiol Biomarkers Prev 19: 310-318, 2010.

13. Dechakhamphu S, Yong vanit $P$, Nair J, Pinlaor S, Sitthithaworn $P$ and Bartsch H: High excretion of etheno adducts in liver fluke-infected patients: Protection by praziquantel against DNA damage. Cancer Epidemiol Biomarkers Prev 17: 1658-1664, 2008.

14. Thanan R, Oikawa S, Yongvanit P, Hiraku Y, Ma N, Pinlaor S, Pairojkul C, Wongkham C, Sripa B, Khuntikeo N, et al: Inflammation-induced protein carbonylation contributes to poor prognosis for cholangiocarcinoma. Free Radic Biol Med 52: $1465-1472,2012$

15. Guner G, Islekel H, Oto O, Hazan E and Açikel U: Evaluation of some antioxidant enzymes in lung carcinoma tissue. Cancer Lett 103: 233-239, 1996.

16. Hofseth LJ, Khan MA, Ambrose M, Nikolayeva O, Xu-WelliverM, Kartalou M, Hussain SP, Roth RB, Zhou X, Mechanic LE, et al: The adaptive imbalance in base excision-repair enzymes generates microsatellite instability in chronic inflammation. J Clin Invest 112: 1887-1894, 2003.

17. Loilome W, Kadsanit S, Namwat N, Techasen A, Puapairoj A, Dechakhamphu A, Pinitsoontorn $\mathrm{C}$ and Yongvanit P: Impaired antioxidant enzyme activity and increased DNA repair enzyme expression in hamster liver tissues related to cholangiocarcinoma development. Asian Pac J Cancer Prev (13 Suppl) S59-S64, 2012

18. Boland CR, Thibodeau SN, Hamilton SR, Sidransky D, Eshleman JR, Burt RW, Meltzer SJ, Rodriguez-Bigas MA, Fodde R, Ranzani GN and Srivastava S: A National Cancer Institute Workshop on Microsatellite Instability for cancer detection and familial predisposition: Development of international criteria for the determination of microsatellite instability in colorectal cancer. Cancer Res 58: 5248-5257, 1998.

19. Scibior D, Skrzycki M, Podsiad M and Czeczot H: Glutathione level and glutathione-dependent enzyme activities in blood serum of patients with gastrointestinal tract tumors. Clin Biochem 41: $852-858,2008$

20. Baker AM, Oberley LW and Cohen MB: Expression of antioxidant enzymes in human prostatic adenocarcinoma. Prostate 32: 229-233, 1997.

21. Jaruga P, Zastawny TH, Skokowski J, Dizdaroglu M and Olinski R: Oxidative DNA base damage and antioxidant enzyme activities in human lung cancer. FEBS Lett 341: 59-64, 1994

22. Beevi SS, Rasheed AM and Geetha A: Evaluation of oxidative stress and nitric oxide levels in patients with oral cavity cancer. Jpn J Clin Oncol 34: 379-385, 2004

23. Itatsu K, Sasaki M, Yamaguchi J, Ohira S, Ishikawa A, Ikeda H, Sato Y, Harada K, Zen Y, Sato H, et al: Cyclooxygenase-2 is involved in the up-regulation of matrix metalloproteinase-9 in cholangiocarcinoma induced by tumor necrosis factor-alpha. Am J Pathol 174: 829-841, 2009.
24. Pinlaor S, Hiraku Y, Yongvanit P, Tada-Oikawa S, Ma N, Pinlaor P, Sithithaworn P, Sripa B, Murata M, Oikawa S and Kawanishi S: iNOS-dependent DNA damage via NF-kappaB expression in hamsters infected with Opisthorchis viverrini and its suppression by the antihelminthic drug praziquantel. Int J Cancer 119: 1067-1072, 2006.

25. Wu T: Cyclooxygenase-2 and prostaglandin signaling in cholangiocarcinoma. Biochim Biophys Acta 1755: 135-150, 2005.

26. Prawan A, Buranrat B, Kukongviriyapan U, Sripa B and Kukongviriyapan V: Inflammatory cytokines suppress NAD (P)H: Quinone oxidoreductase-1 and induce oxidative stress in cholangiocarcinoma cells. J Cancer Res Clin Oncol 135: 515-522, 2009.

27. Yongvanit P, Thanan R, Pinlaor S, Sithithaworn P, Loilome W, Namwat N, Techasen A and Dechakhamphu S: Increased expression of TLR-2, COX-2 and SOD-2 genes in the peripheral blood leukocytes of opisthorchiasis patients induced by Opisthorchis viverrini antigen. Parasitol Res 110: 1969-1977, 2012.

28. Wu Z, Boonmars T, Boonjaraspinyo S, Nagano I, Pinlaor S, Puapairoj A, Yongvanit P and Takahashi Y: Candidate genes involving in tumorigenesis of cholangiocarcinoma induced by Opisthorchis viverrini infection. Parasitol Res 109: 657-673, 2011.

29. Kolodziejczyk L, Siemieniuk E and Skrzydlewska E: Antioxidant potential of rat liver in experimental infection with Fasciola hepatica. Parasitol Res 96: 367-372, 2005.

30. el Ghissassi F, Barbin A, Nair J and Bartsch H: Formation of 1,N6-ethenoadenine and 3, N4-ethenocytosine by lipid peroxidation products and nucleic acid bases. Chem Res Toxicol 8: 278-283, 1995.

31. Nair J, De Flora S, Izzotti A and Bartsch H: Lipid peroxidation-derived etheno-DNA adducts in human atherosclerotic lesions. Mutat Res 621: 95-105, 2007.

32. Singer B and Hang B: Mammalian enzymatic repair of etheno and para-benzoquinone exocyclic adducts derived from the carcinogens vinyl chloride and benzene. IARC Sci Publ: 233-247, 1999.

33. Bohr VA: Repair of oxidative DNA damage in nuclear and mitochondrial DNA, and some changes with aging in mammalian cells. Free Radic Biol Med 32: 804-812, 2002.

34. Liengswangwong U, Nitta T, Kashiwagi $\mathrm{H}$, Kikukawa $\mathrm{H}$, Kawamoto T, Todoroki T, Uchida K, Khuhaprema T, Karalak A, Srivatanakul P and Miwa M: Infrequent microsatellite instability in liver fluke infection-associated intrahepatic cholangiocarcinomas from Thailand. Int J Cancer 107: 375-380, 2003.

35. Losso GM, Moraes Rda S, Gentili AC and Messias-Reason IT: Microsatellite instability-MSI markers (BAT26, BAT25, D2S123, D5S346, D17S250) in rectal cancer. Arq Bras Cir Dig 25: 240-244, 2012 (In English, Portuguese).

36. Saridaki Z, Souglakos J and Georgoulias V: Prognostic and predictive significance of MSI in stages II/III colon cancer. World J Gastroenterol 20: 6809-6814, 2014.

37. Glassner BJ, Rasmussen LJ, Najarian MT, Posnick LM and Samson LD: Generation of a strong mutator phenotype in yeast by imbalanced base excision repair. Proc Natl Acad Sci USA 95: 9997-10002, 1998.

38. Posnick LM and Samson LD: Imbalanced base excision repair increases spontaneous mutation and alkylation sensitivity in Escherichia coli. J Bacteriol 181: 6763-6771, 1999.

39. Jones LE Jr, Ying L, Hofseth AB, Jelezcova E, Sobol RW, Ambs S, Harris CC, Espey MG, Hofseth LJ and Wyatt MD: Differential effects of reactive nitrogen species on DNA base excision repair initiated by the alkyladenine DNA glycosylase. Carcinogenesis 30: 2123-2129, 2009 .

40. Zmudzka BZ, Fornace A, Collins J and Wilson SH: Characterization of DNA polymerase beta mRNA: Cell-cycle and growth response in cultured human cells. Nucleic Acids Res 16: 9587-9596, 1988 .

41. Canitrot Y, Cazaux C, Fréchet M, Bouayadi K, Lesca C, Salles B and Hoffmann JS: Overexpression of DNA polymerase beta in cell results in a mutator phenotype and a decreased sensitivity to anticancer drugs. Proc Natl Acad Sci USA 95: 12586-12590, 1998.

42. Bergoglio V, Pillaire MJ, Lacroix-Triki M, Raynaud-Messina B, Canitrot Y, Bieth A, Garès M, Wright M, Delsol G, Loeb LA, et al: Deregulated DNA polymerase beta induces chromosome instability and tumorigenesis. Cancer Res 62: 3511-3514, 2002.

43. Yamada NA and Farber RA: Induction of a low level of microsatellite instability by overexpression of DNA polymerase Beta. Cancer Res 62: 6061-6064, 2002. 